\title{
ON THE INFLUENCE OF CROSS-ROLLING ON SHEAR BAND FORMATION AND TEXTURE EVOLUTION IN LOW CARBON STEEL SHEETS
}

\author{
M. Y. HUH ${ }^{1}$, O. ENGLER ${ }^{2}$ and D. RAABE ${ }^{2}$ \\ ${ }^{1}$ Department of Metallurgical Engineering, Korea University, Seoul 136-701, Korea \\ ${ }^{2}$ Institut für Metallkunde und Metallphysik, RWTH Aachen, 52056 Aachen, \\ Germany
}

(Received 24 March 1995; in final form 21 April 1995)

\begin{abstract}
In order to understand the influence of the crystallographic texture and the dislocation structure on the deformation mechanism in low carbon steels, the development of the texture and the microstructure in cross-rolled specimens was investigated by employing X-ray texture measurements and TEM observations. The cross-rolled specimens were obtained by rotating the rolling direction by various angles up to $90^{\circ}$ after $30 \%$ initial straight-rolling of the hot rolled band. Whereas only few shear bands were found in the straight-rolled specimen even after heavy deformation, in the cross-rolled specimen shear bands were often found at reductions in excess of $60 \%$. This observation is discussed in terms of the rotation of the arrangement of dislocations and microbands during cross-rolling. The rolling textures observed in the various samples were interpreted by means of Taylor type deformation models.
\end{abstract}

KEY WORDS: low carbon steels, cross-rolling, shear bands, microbands, rolling textures, TEM.

\section{INTRODUCTION}

In the cold rolling textures of low carbon steel sheets preferred orientations with $\{111\} \| N^{*}$ ) and with <110>\|RD*) typically develop (Wassermann, Grewen 1969). The orientation distribution function (ODF) of these preferred orientations can be described by two fibres in the three dimensional Euler orientation space, the $\gamma$ - fibre with \{111\}|IND and the $\alpha$ - fibre with <110>|IRD (e.g. Hutchinson, 1984, v. Schlippenbach et al., 1986, Kern et al., 1986, Inagaki, 1988, Raabe, Lücke, 1994). According to studies of statistical X-ray texture measurements and the observation of the deformation microstructures in transmission electron microscopes (TEM), the rolling texture in low carbon steel sheets is essentially determined by the hot rolling texture and the slip behaviour during cold rolling. The deformation structure existing in rolled steel sheets is not homogeneous, but various inhomogenous deformation mechanisms were found (Mathur, Backofen, 1973, Haratani et al., 1984, Huh et al., 1988, 1995).

Cross-rolling is a rolling process in which the direction of rolling is varied between the rolling passes (e.g. Böcker et al., 1990). In the present work, cross-rolling is referred

$\left.{ }^{*}\right)$ RD: rolling direction, TD: transverse direction and ND: normal direction of the sample coordinate system 


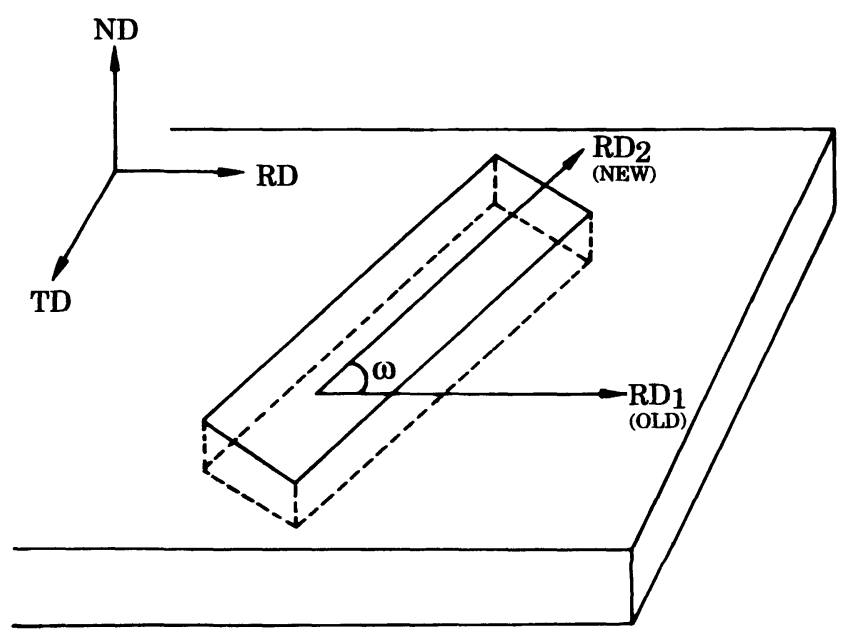

Figure 1 Schematic sketch of the cross-rolling as employed in the present study (the angle $\omega$ denotes the cross-rolling angle, i. e. the rotation of $\mathrm{RD}$ after $30 \%$ reduction.

to as a procedure in which the RD was rotated only once after the first rolling (i.e. straight-rolling parallel $\mathrm{RD}_{1}$ ) reached a certain amount of cold reduction $(30 \%)$. The new rolling direction $\mathrm{RD}_{2}$ which formed a constant angle $\omega$ with respect to the original $\mathrm{RD}_{1}\left(\omega=30^{\circ}, 45^{\circ}, 60^{\circ}\right.$ or $\left.90^{\circ}\right)$ was maintained during the further deformation. Consequently, by changing the RD the texture and the dislocation structure of the crossrolled specimens were rotated by the same angle $\omega$ about ND (Figure 1).

In order to understand the influence of the change in the texture and the dislocation structure due to the cross-rolling on the deformation mechanism during further deformation, the development of the texture and the microstructure were investigated by using X-ray texture measurements and TEM observations. The results obtained in the experiments were interpreted by the crystal orientation rotation theory based on Taylor deformation models.

\section{EXPERIMENTAL PROCEDURE}

The low carbon steel sheet used in this study was the hot coil with a thickness of $3.5 \mathrm{~mm}$ manufactured by POSCO, South Korea. The grain size of the hot coil was $\sim 30 \mu \mathrm{m}$, the finishing temperature was $920^{\circ} \mathrm{C}$ and the coiling temperature was $725^{\circ} \mathrm{C}$. Table 1 shows the chemical composition of the steel. Further deformation of this sheet was carried out by reversingly cold rolling using a laboratory rolling mill with a roll

Table 1 Chemical composition of the deep drawing steel (wt.\%).

\begin{tabular}{lcccccccccc}
\hline $\mathrm{C}$ & $\mathrm{Mn}$ & $\mathrm{Si}$ & $\mathrm{P}$ & $\mathrm{S}$ & $\mathrm{Cu}$ & $\mathrm{Ni}$ & $\mathrm{Cr}$ & $\mathrm{Ti}$ & $\mathrm{Al}$ & $\mathrm{Al}$ \\
\hline & & & & & & & & & total & solute \\
\hline 0.004 & 0.13 & 0.01 & 0.014 & 0.008 & 0.01 & 0.01 & 0.01 & 0.038 & 0.039 & 0.01 \\
\hline
\end{tabular}


diameter of $127 \mathrm{~mm}$. First, the specimens were rolled to $30 \%$ thickness reduction with $\mathrm{RD}_{1}$ parallel to the former hot rolling direction, which corresponds to a true strain of $\varepsilon=\operatorname{In}\left[\frac{t_{o}}{t}\right]=0.36$. The cross-rolling specimens were then obtained by cutting the steel sheet under different angles to $\mathrm{RD}_{1}$ as indicated in Figure 1. These specimens were rolled to a total reduction of $50 \%(\varepsilon=0.7), 60 \%(\varepsilon=0.9), 70 \%(\varepsilon=1.2)$ or $80 \%(\varepsilon=1.6)$ while maintaining the new $\mathrm{RD}_{2}$. The deformation degrees of the samples in the present paper are always expressed in terms of the total thickness reduction. Thus, a $60 \%$ rolled specimen with a cross-rolling angle of $45^{\circ}$ denotes that the second rolling degree is $30 \%$ after a $45^{\circ}$ rotation of the $R D$.

The rolling textures were determined by measuring pole figures by means of an automated X-ray texture goniometer (Hirsch et al., 1984). From four incomplete pole figures $\{011\},\{002\},\{112\}$ and $\{013\}$ the orientation distribution functions (ODF) $f(g)$ were calculated according to the series expansion method by Bunge (1969) with $1_{\max }=22$, with the orientation $g$ being expressed in form of the corresponding Euler angles $\varphi_{1}, \phi, \varphi_{2}$. For the calculation of the ODFs only the even order C-coefficients were used as the textures of ferrite steels are only weakly affected by ghost errors (e.g. v. Schlippenbach et al., 1986). In order to yield comparability with commercially produced steel sheets, all ODF calculations were performed under the assumption of orthorhombic sample symmetry, i.e. $0^{\circ} \leq \varphi_{1}, \phi, \varphi_{2} \leq 90^{\circ}$.

For TEM investigations, an observation in the rolling plane (RD/TD) of rolled specimen is not suitable, but commonly more information of the deformed structure is obtained from the longitudinal section (RD/ND). Thus, the observation direction was the transverse direction (TD). The specimens with high reduction degrees were too thin for preparation of longitudinal sections and, therefore, they were electroplated with nickel for TEM investigations.

\section{EXPERIMENTAL RESULTS}

\subsection{Microstructure and texture after 30\% straight-rolling}

Figure $2 \mathrm{a}$ shows the microbands formed in the longitudinal section of the $30 \%$ cold rolled specimen. At $30 \%$ reduction microbands were observed in most of the grains. The microbands formed parallel to each other and their walls were typically developed near $35^{\circ}$ with respect to $\mathrm{RD}$ in the longitudinal sections. In the literature this type of microband arrays is called a microband cluster (Malin, Hatherly, 1979, Huh et al., 1986, 1988). A microband cluster represents a dislocation structure in which dislocation slip is concentrated on a specific slip plane in a given grain. The dislocation density at the microband walls was substantially higher than that inside of the microband cells. However, selected area diffraction (SAD) patterns obtained from the regions with microband clusters exhibited only minor local orientation differences not exceeding a few degrees.

Figure 3 shows the ODF of the texture after $30 \%$ straight-rolling. The maximum orientation density $f(g)=6.2$ was found at $\left(\varphi_{1}, \phi, \varphi_{2}\right)=\left(0^{\circ}, 0^{\circ}, 45^{\circ}\right)$ which is equivalent to $\{001\}<110>$. The orientations lying between $\left(0^{\circ}, 0^{\circ}, 45^{\circ}\right)$ and $\left(0^{\circ}, 60^{\circ}, 45^{\circ}\right)$ form the $\{\mathrm{hkl}\}<110>\alpha$ - fibre in the $\varphi_{1}=0^{\circ}$ section in the Euler orientation space. The $\gamma$ - fibre with $\{111\}<u v w>$ penetrates all $\varphi_{1}$ - sections at $\phi=55^{\circ}$ and $\varphi_{2}=45^{\circ}$ in the ODFs. 


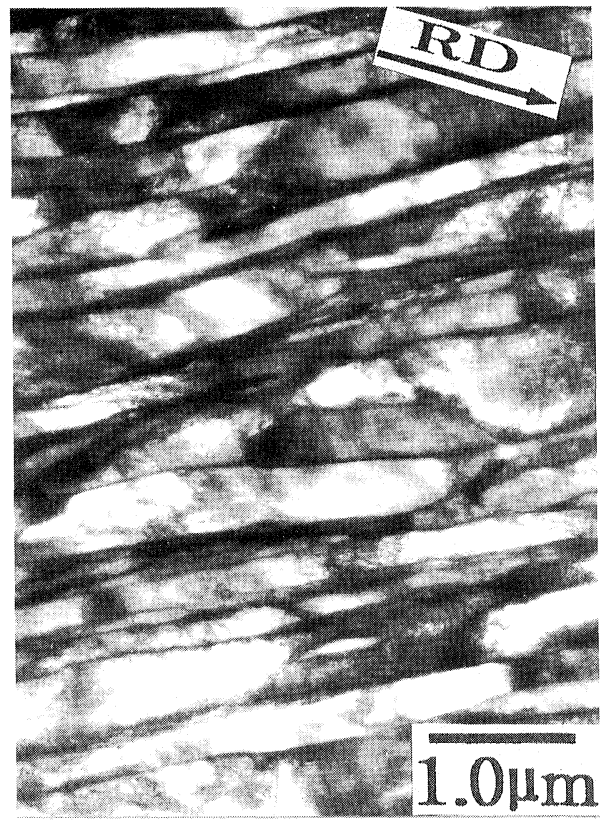

(a)

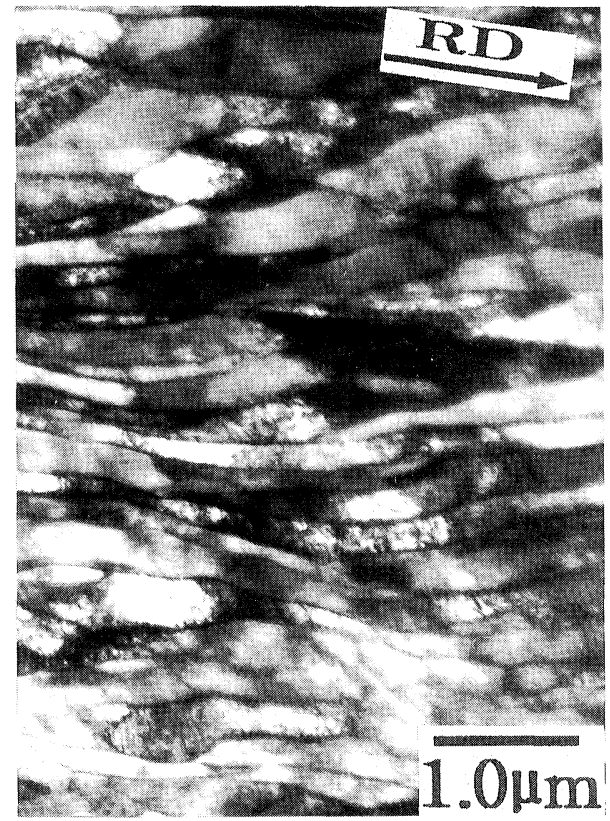

(b)

Figure 2 Microbands formed in the straight-rolled specimen (TEM, longitudinal section) (a) $30 \%$ red. (b) $80 \%$ red.

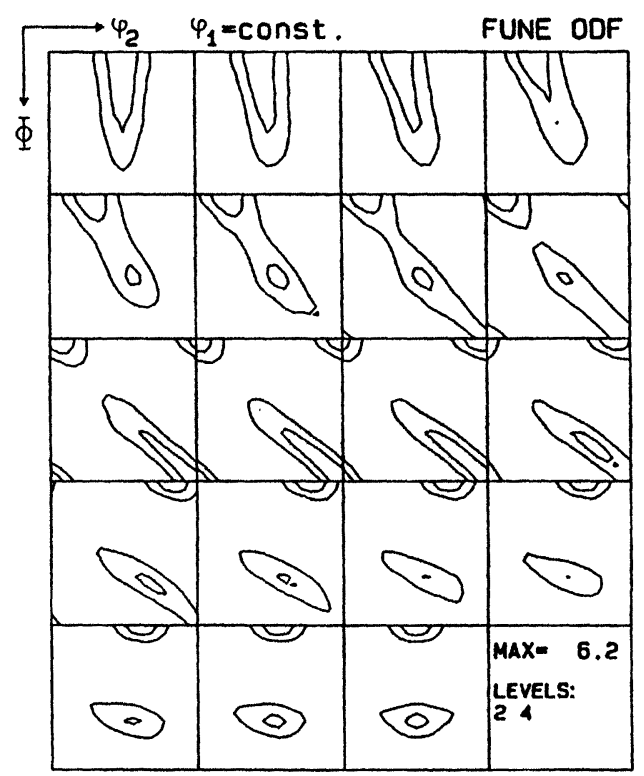

Figure 3 ODF of the $30 \%$ straight-rolled specimen. 


\subsection{Influence of cross-rolling on the microstructure}

Figure 4 shows the microstructure of the $50 \%$ rolled specimen with a cross-rolling angle of $\omega=60^{\circ}$. The microband cluster lay at $\sim 10^{\circ}$ to $\mathrm{RD}_{2}$ in the longitudinal section. The microband walls lay parallel to each other, and the thickness of microbands was $\sim 0.25 \mu \mathrm{m}$.

In the microstructure of the $70 \%$ rolled specimen with a cross-rolling angle of $\omega=60^{\circ}$ the development of shear bands was observed, an example is depicted in Figure 5. The shear bands caused a marked shear displacement in the microband cluster. In this longitudinal section the microbands lay almost parallel to $\mathrm{RD}_{2}$ and the shear band developed at $\sim 30^{\circ}$ to $\mathrm{RD}_{2}$. The matrix orientation as determined by $\mathrm{SAD}$ was close to $\{111\}<112>$, and the orientation was uniform throughout the microband cluster. However, in the vicinity of all shear bands an orientation scattering of several degrees was found (cf. Haratani et al., 1984, Wagner et al., 1995), the magnitude of this scattering being different at each shear band. Since the relative volume of shear bands was very small as compared to the matrix volume, the determination of the orientation of a shear band was not possible by using SAD. Similar to previous work (Huh et al., 1986, 1988), virtually no shear band formation was observed at reductions higher than $80 \%$ in the straight-rolled specimens (Figure $2 \mathrm{~b}$ ). The crossrolled specimens, in contrast, revealed substantial development of shear bands at reduction degrees exceeding $70 \%$ (Figure 5).

\subsection{Influence of cross-rolling on the texture}

In Figure 6 the $\{011\}$-pole figures of the $50 \%$ and the $80 \%$ rolled samples are depicted for the various cross-rolling angles $\omega$. Whereas at $50 \%$ reduction the pole

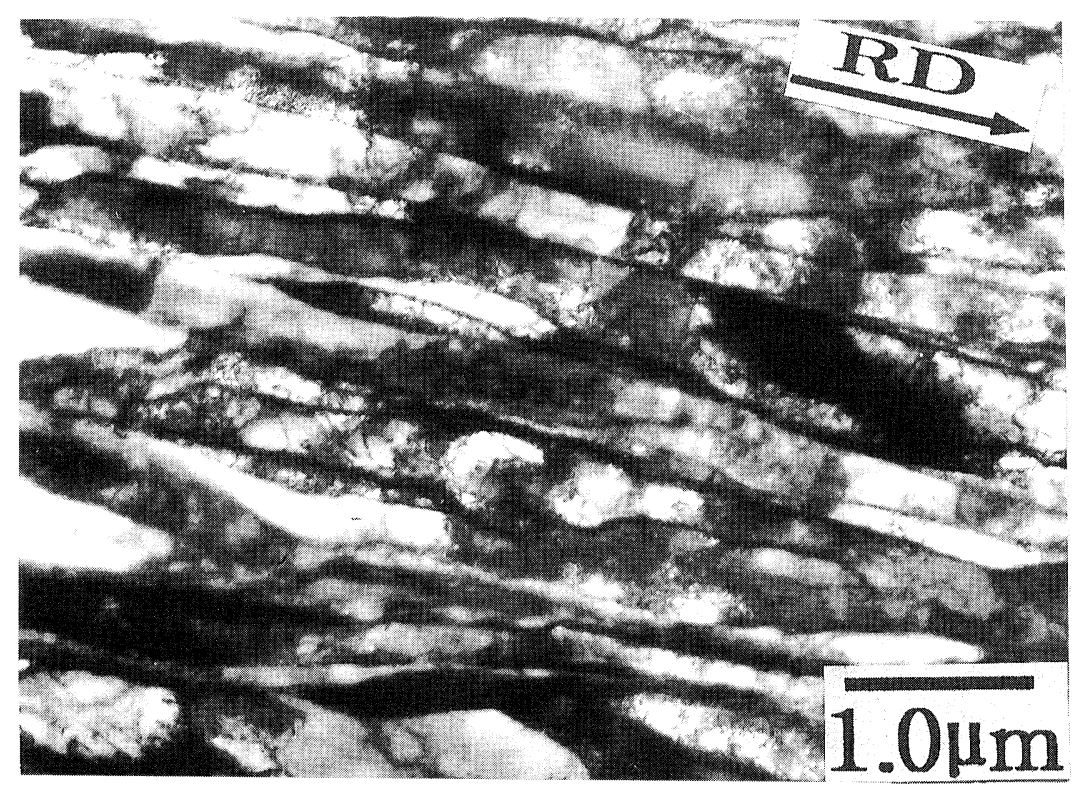

Figure 4 Microstructure of the $50 \%$ cold rolled specimen with a cross-rolling angle of $60^{\circ}$ (TEM, longitudinal section) 


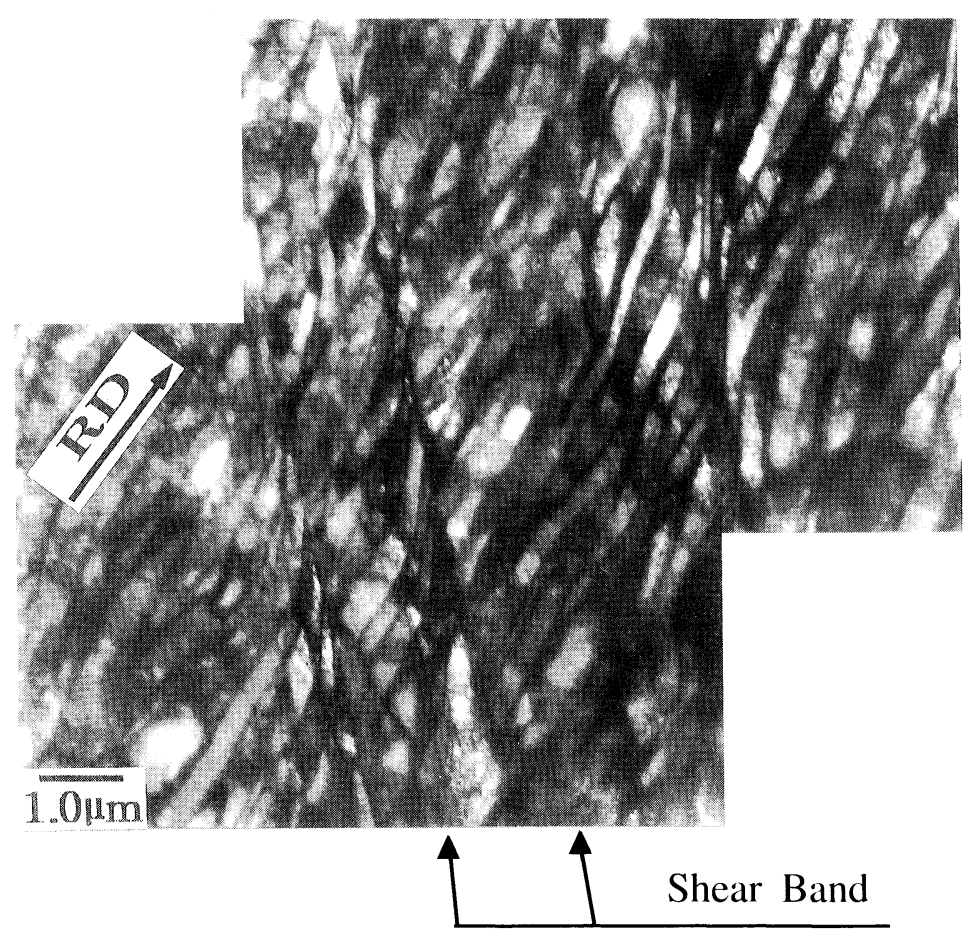

Figure 5 Microstructure of the $70 \%$ cold rolled specimen with a cross-rolling angle of $60^{\circ}$. showing the development of a shear band (TEM, longitudinal section).

figures of the cross rolled samples still exhibited deviations from the orthorhombic sample symmetry, at $80 \%$ reduction the assumption of orthorhombic sample symmetry is nearly fulfilled (Sec. 2). In the ODFs, most of the important information about the texture of low carbon steel sheets can be found in the $\varphi_{1}=0^{\circ}$ and $90^{\circ}$ sections. Therefore, the representation of the texture development in the straight-rolled and in the cross-rolled specimens in Figure 7 is confined to these sections.

A cross-rolling angle of $\omega=0^{\circ}$ denotes straight-rolling. With increasing reduction degree, the $\alpha$ - fibre orientations $\{001\}<110>,\{112\}<110>$ and $\{111\}<110>$ became the major orientations in the rolling texture of the straight-rolled samples. The density of the $\gamma$ - fibre intensified as well with in increasing reduction. In the $80 \%$ straightrolled specimen the maximum orientation density was found at $\{111\}<110>$ where both fibres intersect.

The rotation of RD during the cross-rolling resulted in a marked change in the textures of the $50 \%$ cross-rolled specimens (cf. Böcker et al., 1990). The $\alpha$-fibre orientations which were very pronounced after straight rolling $(f(g)>4)$ had nearly disappeared in the cross-rolled specimens with the exception of $\{111\}<110>$ (Figure 7). Instead, preferred orientation formed at $\phi=0^{\circ}$ in the $\varphi_{1}=0^{\circ}$ section with the angle $\varphi_{2}$ varying with the cross rolling angle $\omega$ : In the $30^{\circ}, 45^{\circ}, 60^{\circ}$ and $90^{\circ}$ cross-rolled specimens orientations close to $\left(0^{\circ}, 0^{\circ}, 15^{\circ}\right),\left(0^{\circ}, 0^{\circ}, 0^{\circ}\right),\left(0^{\circ}, 0^{\circ}, 15^{\circ}\right)$, and $\left(0^{\circ}, 0^{\circ}, 45^{\circ}\right)$, respectively, and their symmetrically equivalent orientations were observed. The 
ON THE INFLUENCE OF CROSS-ROLLING
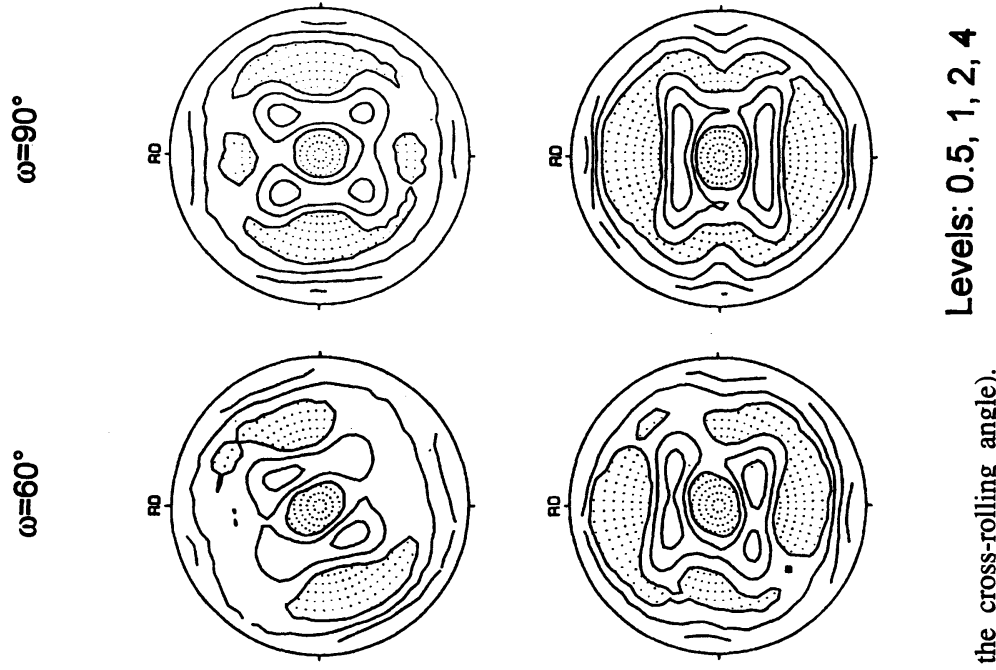

高
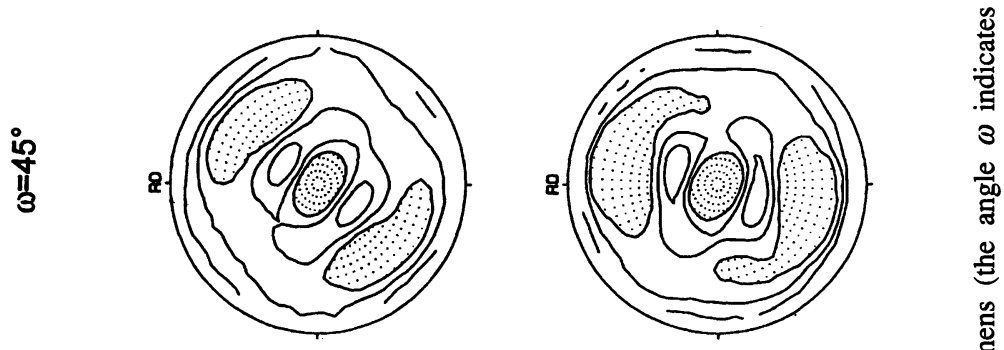

忥
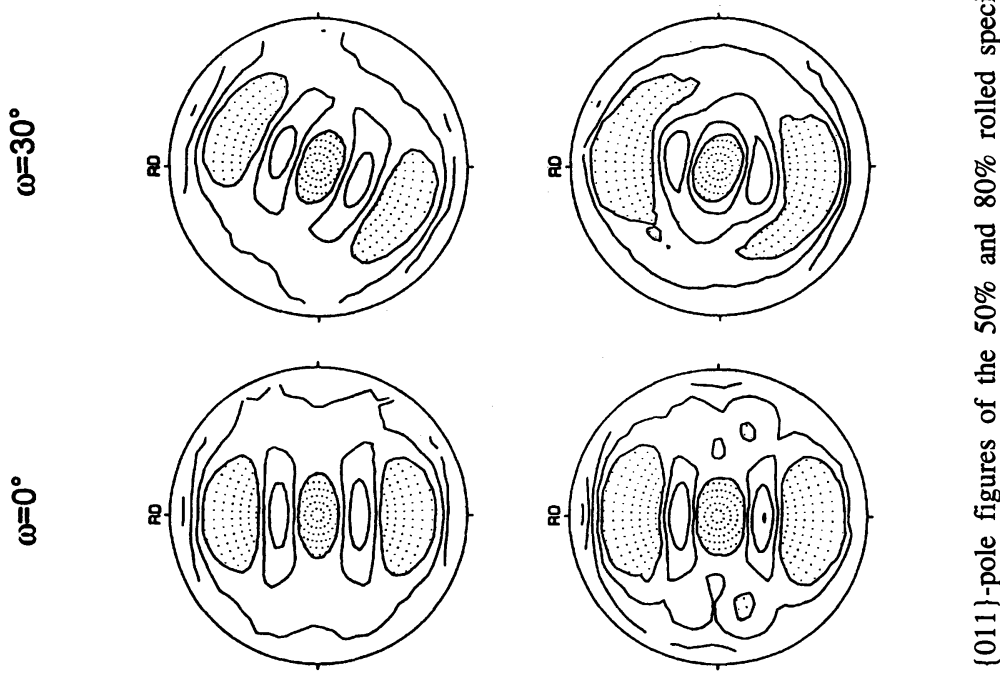

总 高

承离

○ 


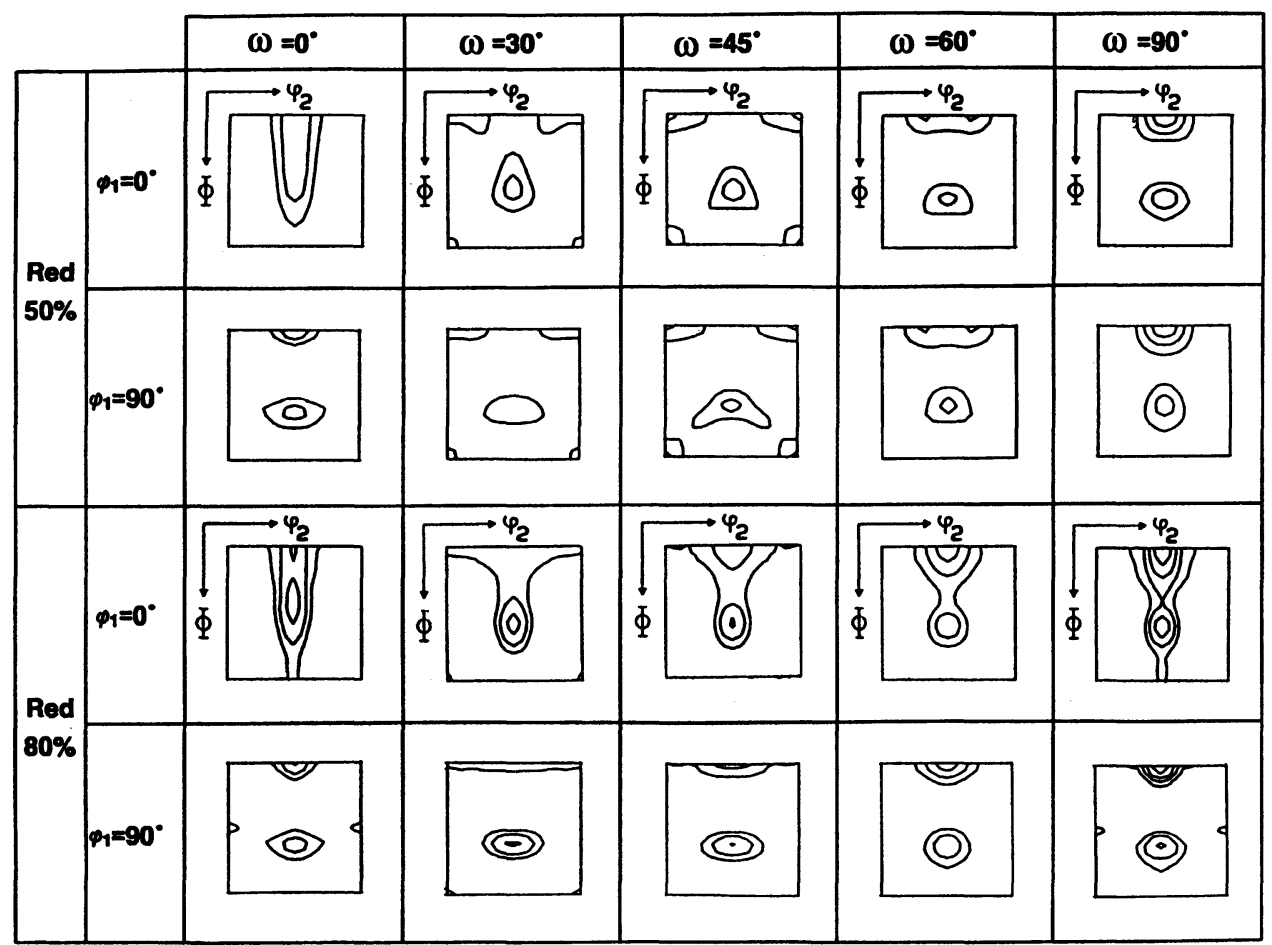

Levels: 2, 4, 7, 12, 20, 30

Figure 7 Development of rolling textures in $\varphi_{1}=0^{\circ}$ and $90^{\circ}$ sections after $50 \%$ and $80 \%$ total reduction (the angle $\omega$ indicates the cross-rolling angle).

orientations along the $\gamma$ - fibre, in contrast, remained mainly unaffected by the cross rolling (Figure 7).

With increasing deformation the influence of the cross-rolling became less pronounced. After $80 \%$ reduction, the textures of all specimens showed similar orientation distributions which can be described by the $\alpha-$ and $\gamma$ - fibre (Figure 7). However, it is interesting to note that there was still a tendency to form orientations with $\varphi_{1}=0^{\circ}$ and $\phi=0^{\circ}$, and in the $90^{\circ}$ cross-rolled specimen the orientation $\left(0^{\circ}, 0^{\circ}, 45^{\circ}\right)$ even formed the texture maximum.

\section{DISCUSSION}

\subsection{Development of the microstructure}

The formation of the deformed microstructure observed in the straight-rolled specimen was identical to that of previous work (Huh et al., 1986, 1988). Equiaxed cells were formed by homogeneous slip at low reduction degrees. After the specimen was hardened to a certain degree, microbands were observed in the longitudinal section of the rolled specimen. It is known that inhomogeneous slip on discrete planes is responsible for 
the formation of microbands in deformed materials (Malin, Hatherly, 1979, Huh et al., 1986,1988 ). After $30 \%$ reduction microbands developed parallel to each other to form an array of microband clusters in most of the grains as shown in Figure 2a. Microband clusters lay at about $\pm 35^{\circ}$ to the RD in the longitudinal sections, and the walls of microbands lay parallel to the rolling plane in the transverse sections (TD/ND). Figure 8a shows a schematic illustration of the dislocation structure in the $30 \%$ straight-rolled specimen where the microbands are indicated by their walls. During further straight-rolling the microband clusters were rotated and elongated by the corresponding plastic strain of the rolled specimen. The rotation and the elongation of the microbands led to a dislocation structure in the longitudinal section as depicted in Figure $8 \mathrm{~b}$. This type of microband morphology was observed in many grains after $70-80 \%$ straight-rolling reduction, an example is shown in Figure $2 \mathrm{~b}$. In this state, the microbands were thinner and slightly more bent than after $30 \%$ reduction, and they were situated more or less parallel to the RD.

The mechanism of shear band formation can be explained by a microstructural instability which is related to a localized softening like the necking in a tensile specimen (Dillamore et al., 1979). It was reported already earlier (Mathur, Backofen 1973, Huh et al., 1986, 1988) that shear bands in low carbon steel were found only in heavily work hardened microstructures in which besides the dislocation slip an additional deformation mechanism was needed in response to the deformation of the rolled specimen. A localized microstructural inhomogeneity formed at the shear band since the shear strain was limited and concentrated at the developing shear band. Only few shear bands were found in the straight-rolled specimens even at $80 \%$ reduction. In $30-80 \%$ straight-rolled specimens the major deformation mechanism observed in the microstructure was the formation of new microbands and their subsequent elongation. The movement of dislocations in a grain with microband clusters seems to be confined to the interior of a microband, because the dislocation density at the microband walls was much higher than that inside the microbands. Therefore, the rotation of microband walls towards RD and the elongation of microbands in the longitudinal sections with increasing deformation can be explained by the limited mobility of dislocations within the microbands.

In contrast to the straight-rolled specimens, shear bands were often found in the longitudinal sections of the cross-rolled specimens at reductions in excess of $60 \%$, as e.g. apparent in Figure 5. The development of shear bands in cross-rolled specimens implies that the degree of work hardening in the cross-rolled specimens was larger than that in a straight-rolled specimen. Cross-rolling was performed with a new $\mathrm{RD}_{2}$ with an angle $\omega$ to the original $\mathrm{RD}_{1}$ (Figure 1, Sec. 2) and, therefore, the dislocation structure in the cross-rolled specimens was rotated by the same angle $\omega$. Whereas a rotation of $\mathrm{RD}$ does obviously not affect the total dislocation density of the specimen, the dislocation configuration with regard to the new reference axes of the cross-rolled specimen has undergone a rotation by the cross-rolling angle $\omega$. Figures $8 \mathrm{c}$ and $\mathrm{d}$ show a schematic sketch of this configuration immediately after changing RD by $60^{\circ}$ and $90^{\circ}$, respectively.

Under the strain state of rolling the slip planes of the active slip systems are generally inclined to RD in the longitudinal sections. In case that the microband walls lie parallel to $\mathrm{RD}$ as shown in Figure 8d, the dislocation current should thus to a certain extend penetrate the microband walls. This fact that crystallographic slip is accompanied by cutting of microband walls strongly suggests that slip is considerably impeded in the cross-rolled specimens. Therefore, it is concluded that the onset of 


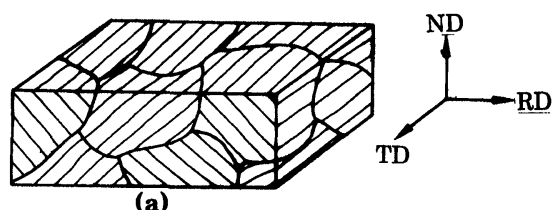

(a)

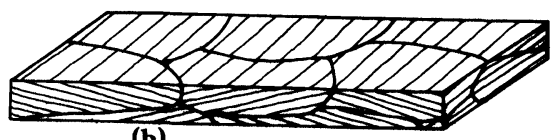

(b)
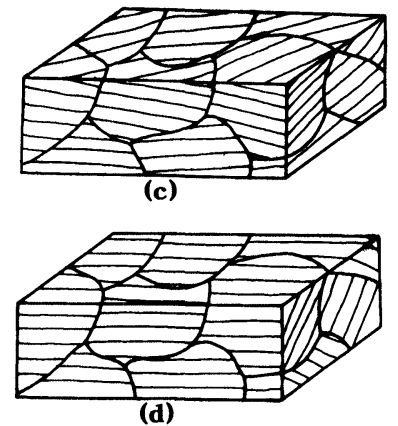

Figure 8 Schematic illustration of the microstructural change by straight-rolling and by cross-rolling.

(a) Grains with microband cluster after $30 \%$ reduction;

(b) rotation and elongation of the microband cluster during straight-rolling;

(c) microstructure after a rotation of $\mathrm{RD}$ by $60^{\circ}$;

(d) microstructure after a rotation of RD by $90^{\circ}$.

shear banding in the cross-rolled specimens is related to the microstructurally hardened dislocation structure, where beside slip an additional deformation mechanism is needed to accomplish further deformation. The formation of shear bands is a typical mechanism of inhomogeneous deformation which occurs in low carbon steels since a large shear displacement is localized merely in the developing shear band.

\subsection{Development of the texture}

The rolling texture of the straight-rolled specimen can be described by the two typical fibres, the $\alpha$ - and the $\gamma$ - fibre (e.g. Hutchinson, 1984, v. Schlippenbach et al., 1986, Kern et al., 1986, Inagaki, 1988, Raabe, Lücke, 1994). The development of the preferred orientations along these fibres in low carbon steel sheets can readily be simulated by means of Taylor type deformation models with relaxed $\varepsilon_{\mathrm{RD} / \mathrm{ND}^{-}}$and $\varepsilon_{\mathrm{TD} / \mathrm{ND}^{-}}$shears (relaxed constraints Taylor models) employing $\{110\},\{112\}$ and $\{123\}$ slip planes with identical critical resolved shear stresses (Raabe, Lücke, 1994). As an example, in Figure 9 the simulated rolling texture is represented in terms of the $\varphi_{1}=0^{\circ}$ and $\varphi_{1}=90$-sections of the ODF. A rather good resemblance between this simulated texture (Figure 9; $\omega=0^{\circ}$ ) and the experimentally observed straight-rolling texture (Figure 7) is evident. For a more detailed discussion of the simulation of rolling textures in steel sheets see e.g. Bunge (1970), Hölscher et al., (1991), Aernoudt et al., (1993). 
A rotation of the $\mathrm{RD}$ in the cross-rolled specimens after $30 \%$ straight-rolling corresponds to a rotation of the entire texture about the ND by the cross-rolling angle $\omega$ (cf. Figure 1). At $50 \%$ reduction, orientations near $\left(0^{\circ}, 0^{\circ}, 15^{\circ}\right),\left(0^{\circ}, 0^{\circ}, 0^{\circ}\right)$, $\left(0^{\circ}, 0^{\circ}, 15^{\circ}\right)$, and $\left(0^{\circ}, 0^{\circ}, 45^{\circ}\right)$ were observed in the specimens cross-rolled with an angle of $30^{\circ}, 45^{\circ}, 60^{\circ}$, and $90^{\circ}$, respectively, as shown in the $\varphi_{1}=0^{\circ}$ section of the ODFs (Figure 7). These orientations can simply be obtained by a rotation of the $\{001\}<110>$ orientation located at $\left(0^{\circ}, 0^{\circ}, 45^{\circ}\right)$, the main texture component in the $30 \%$ straight-rolled specimen (Figure 3 ), by the various cross-rolling angles $\omega$ of each cross-rolled specimen.

Whereas in the straight-rolled specimen at all rolling degrees a strong $\alpha$ - fibre prevailed in the textures, this fibre was not observed in all cross-rolled specimens at $50 \%$ reduction (Figure 7). This reflects the fact that a rotation of the rolling texture about ND leads to orientations which do not belong to the $\alpha$ - fibre. In contrast, the orientation distribution along the $\gamma$ - fibre was not significantly changed in the crossrolled specimens in comparison to the straight-rolled specimen. A rotation of the $\gamma$ - fibre orientations about ND leads to orientations which again are situated at the $\gamma$ - fibre, and thus, cross-rolling did not markedly affect the orientation density along this fibre.

These simple considerations were analysed in a more quantitative manner by performing texture simulations according to the Taylor relaxed constraints model (see above). In order to take the cross-rolling into account, the entire simulated texture was rotated by the cross-rolling angle $\omega$ about ND after simulation up to $30 \%$ straightrolling. The simulation was performed under the assumption of triclinic sample symmetry (i.e. non-symmetrized), but after the simulation the ODFs were symmetrized with respect to the sample symmetry. The simulated rolling textures with a total reduction of $50 \%$ and $80 \%$ are represented in Figure 9 using $\varphi_{1}=0^{\circ}$ and $\varphi_{1}=90^{\circ}$-sections of the ODF for the various cross-rolling angles $\omega$, cf. Figure 7 .

As in case of the straight-rolled specimens, a good resemblance between the simulated and the experimentally observed rolling textures is apparent for both reduction degrees, $50 \%$ and $80 \%$. Although the sharpness of the simulated textures is much higher than in the experimental ones, the textural differences owing to the cross-rolling are qualitatively reproduced by the simulation. The disappearance of the $\alpha-$ fibre in the cross rolled samples at $50 \%$ reduction as well as the rotation of the initial orientation $\{001\}<110>\left(0^{\circ}, 0^{\circ}, 45^{\circ}\right)$ about ND and particularly the strong increase of $\left(0^{\circ}, 0^{\circ}\right.$, $45^{\circ}$ ) in the $80 \%$ cross-rolled samples clearly showed up in the simulation, whereas the $\gamma$ - fibre is less affected. Even the shape of the scatter of the rolling texture orientations in the $\varphi_{1}$ - sections is quite well reproduced. So in conclusion, the effect of cross-rolling on the texture development can be interpreted in terms of the variations of the starting texture, which were artificially generated by rotating the samples after the first $30 \%$ straight-rolling.

With increasing reduction the differences between both the observed and the simulated rolling textures obtained for the various cross-rolling angles became less pronounced. Finally, at $80 \%$ reduction very similar rolling textures were obtained for the straight-rolled and the cross-rolled specimens (Figure 7). This means that the influence of the starting texture (i.e. the rolling texture after $30 \%$ straight-rolling) became less dominant and the rolling texture orientations which usually form upon rolling of bcc metals prevailed.

In the cross-rolled specimens at reductions higher than $60 \%$ profuse shear bands were found, whereas the straight-rolled specimens depicted only few shear bands at 


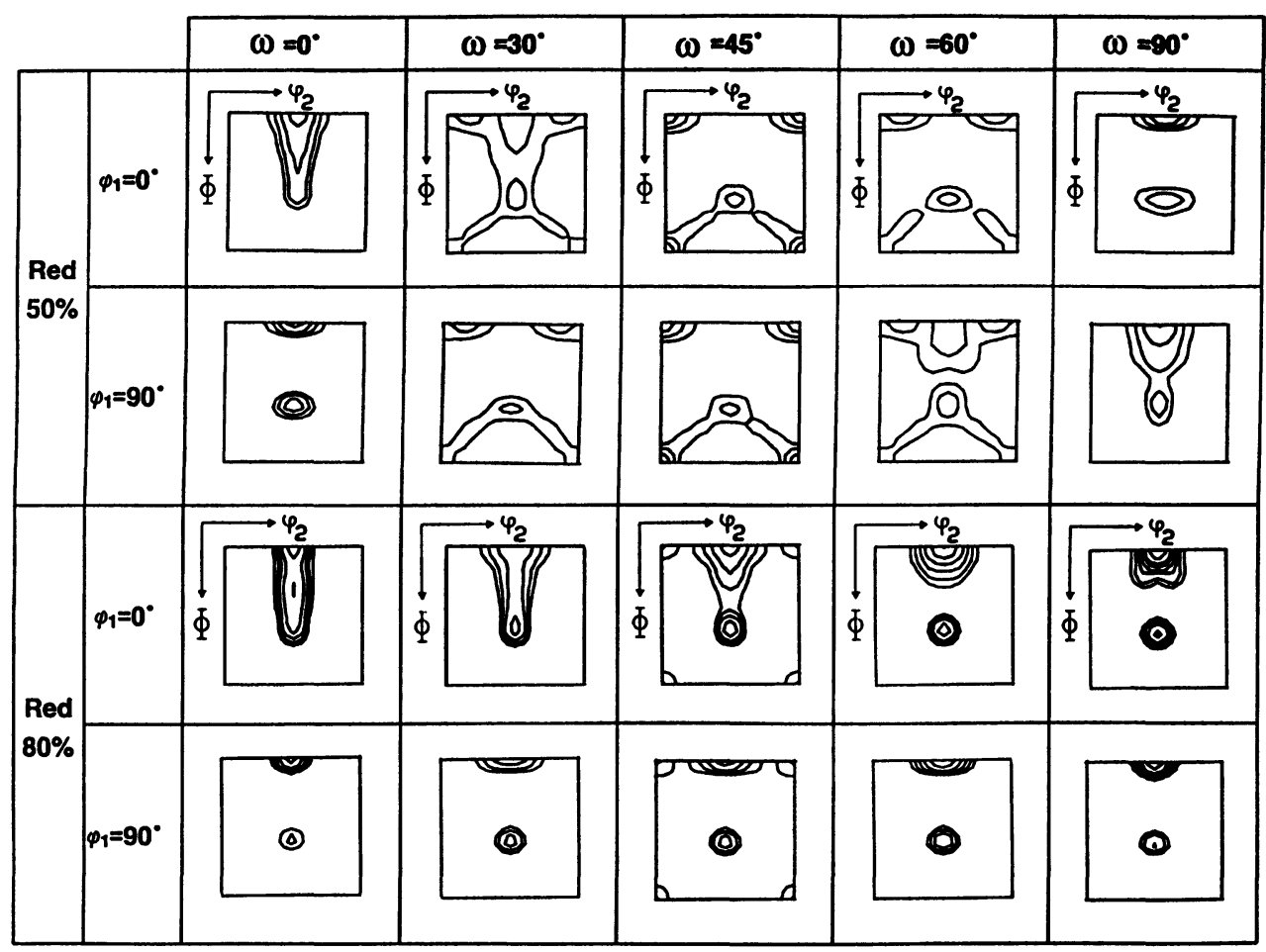

Levels: $2,4,7,12,20,30$

Figure 9 Rolling textures in the $\varphi_{1}=0^{\circ}$ and $90^{\circ}$ sections after simulation up to $50 \%$ and $80 \%$ total reduction (the angle $\omega$ indicates the cross-rolling angle, i.e. the rotation of RD after $30 \%$ reduction; cf. Figure 7).

moderate strains. The orientation at these shear bands was different to the matrix orientation, because the shear strain was limited and concentrated inside the shear band. Nevertheless, a perceivable effect of shear bands on the rolling texture was not found. This means that the orientation distribution of the entire specimen is virtually not affected by the small volume of the shear bands.

\section{SUMMARY AND CONCLUSIONS}

It was the aim of the present study to investigate the influence of cross-rolling on the formation of the dislocation structure and the crystallographic texture during cold rolling of low carbon steels and to draw conclusions about on the deformation mechanisms involved. The cross-rolled specimens were created by rotating the RD by various angles up to $90^{\circ}$ after $30 \%$ initial straight-rolling. The following results were obtained:

1. The development of the microstructure in the straight-rolled samples was characterized by the formation of microbands and their subsequent rotation into the RD. After large reductions additionally some shear bands were observed. These observations are in good agreement with earlier investigations. 
2. A rotation of $\mathrm{RD}$ after the initial $30 \%$ straight-rolling in the cross-rolled specimens led to a rotation of the microband arrays by the cross-rolling angle. The onset of shear banding in the cross-rolled specimens seemed to be related to the microstructurally hardened dislocation structure.

3. The rolling textures of the straight-rolled samples were characterized by typical fibre type textures which mainly comprised the $\alpha$ - fibre $(<110>\| R D)$ and the $\gamma$ - fibre $\{111\} \| N D)$. In the cross-rolled samples, the $\alpha$ - fibre had almost disappeared and, instead, other orientations at $\varphi_{1}=0^{\circ}$ and $\phi=0^{\circ}$ had formed. The $\gamma$ - fibre, in contrast, remained more or less unaffected. As shown by Taylor deformation models, these effects of the cross-rolling can be attributed to the variations of the starting texture that were generated by rotating the samples after the initial $30 \%$ straight-rolling.

4. At large reductions the differences between the rolling textures of the various samples were less pronounced. With increasing reduction the influence of the starting texture (i.e. the rolling texture after $30 \%$ straight-rolling and subsequent rotation) on the evolution of the rolling textures decreased.

\section{Acknowledgements}

The authors want to express their gratitude to Prof. Dr. Dr. h.c. K. Lücke for valuable comments and to Dr. J.H. Kim for performing the TEM work.

\section{References}

Aernoudt, E., van Houtte, P. and Leffers, T. (1993). "Mater Sci. and Tech." (Vol. ed. H. Mughrabi, Ser. eds. R. W. Cahn, P. Haasen, E. J. Kramer), VCH Weinheim, Vol. 6, 89-136.

Böcker, A., Klein, H. and Bunge, H.J. (1990). Textures and Microstructures 12, 103-123.

Bunge, H. J. (1969). "Mathematische Methoden der Texturanalyse", Akademie-Verlag Berlin.

Bunge, H. J. (1970). Kristall u. Technik 5, 145-175.

Dillamore, I. L., Roberts, J. G. and Bush, A. C. (1979). J. Met. Sci. 13, 73-77.

Haratani, T., Hutchinson, W. B., Dillamore, I. L. and Bate, P. (1984). J. Met. Sci. 18, 57-65.

Hirsch, J., Loeck, M., Loof, L. and Lücke, K. (1984). Proc. ICOTOM 7, Noodwijkerhout (1984) 765-771.

Hölscher, M., Raabe, D. and Lücke, K. (1991). Steel research 62, 567-575.

Huh, M. Y. (1986). Dissertation RWTH Aachen.

Huh, M. Y., Engler, O. and Raabe, D. (1995). submitted to steel research.

Huh, M. Y., Hong, J. H. and Lücke, K. (1988). J. of the Korean Inst. of Metals 26, 260-272.

Hutchinson, W. B. (1984). Int. Mat. Rev. 29, 25-42.

Inagaki, H. (1988). Z. Metallk. 79, 164-173.

Kern, R., Lee, H. P. and Bunge, H. J. (1986). Steel research 57, 563-571.

Malin, A. S. and Hatherly, M. (1979). J. Met. Sci. 13, 463-472.

Mathur, P. S. and Backofen, W. A. (1973). Metall. Trans. 4, 643-657.

Raabe, D. and Lücke, K. (1994). Mat. Sci. Forum 157-162, 597-610.

v. Schlippenbach, U., Emren, F. and Lücke, K. (1986). Acta metall. 34, 1289-1301.

Wagner, P., Engler, O. and Lücke, K. (1995). Acta metall. mater. in press.

Wassermann, G. and Grewen, J. (1962). "Texturen metallischer Werkstoffe" Springer Berlin. 